\title{
Agrarian urban architecture
}

\author{
T. Gentry \\ Laboratory for Innovative Housing \\ University of North Carolina, Charlotte, USA
}

\begin{abstract}
In urban areas throughout the United States, the prevailing environmental design measures planners, architects and engineers use to address carbon footprint, water footprint, stormwater runoff, and food deserts are disassociated from one another, which produces suboptimal solutions. Reducing the carbon footprint typically involves scrutinizing the heating, cooling and light equipment. Reducing the water footprint invariably calls for the use of low-flow equipment, greywater systems and xeriscapes. Mitigating stormwater runoff defaults to the incorporation of rain gardens, bio-swales and green roofs. And, eradicating food deserts usually relies on the planning of farmers' markets and community gardens. Missing is the one solution that addresses all four of these concerns agrarian urban architecture. Planting green roofs, rain gardens, bioswales and public spaces with fruits and vegetables transforms urban rainwater from a stormwater management problem to a vital resource for community gardens and urban CSA (community supported agriculture) farms that are widely distributed throughout the urban area, which work to eliminate food deserts. Diverting rainwater away from measures that promote evaporation towards measures that produce food reduces the water footprint. And, producing food locally eliminates the carbon footprint associated with transporting food long distances. The only real challenge is getting this information into the hands of the people who can best effect a change - emerging planners, architects and engineers. This paper recounts a two-year effort to teach agrarian urban architecture by incorporate farming into a multidisciplinary design studio for planning, architecture and engineering students at the University of North Carolina Charlotte. The course pedagogy revolves around the integrated design process to seek environmentally and socially sustainable housing, which must include farming to be comprehensive.
\end{abstract}


Keywords: water footprint, rainwater, integrated design process, architecture, urban farming.

\section{Introduction}

In 1910 the United States citizenry was predominately a rural agrarian population. By 1920 it was predominately an urban population. Providing food for the growing urban population resulted in the number of farms increasing to nearly 7 million by 1935 [1]. During the next 30 years mechanization allowed farmers to work larger farms, which lead to farm consolidation and a sharp decline in the number of farms, and farmers. The transition to fossil fuel based industrial farming in the 1970 s lead to additional farm consolidation, which reduced the number of farms to 1.9 million in 1997 [1]. Today, less than 1 percent of the United States population claims farming as their occupation, [2] and most of them are only familiar with industrial farming. This implies most of the remaining 99 percent of the population - which includes planners, architects and engineers - has no or limited firsthand knowledge of any kind of farming. The result is a significant oversight in seeking environmentally and socially sustainable urban development/design solutions. Realizing this, the author, who is an architect and a professor of architecture, began working with experts in the local food movement to include urban farming in the architecture program at the University of North Carolina Charlotte.

\section{Professional recognition of sustainability development}

In 1990 the American Institute of Architects (AIA) formed the Committee on the Environment, which “... works to advance, disseminate, and advocate - to the profession, the building industry, the academy, and the public - design practices that integrate built and natural systems and enhance both the design quality and environmental performance of the built environment [3]." Six years later the American Society of Civil Engineers (ASCE) “... revised its Code of Ethics to make the principles of sustainable development part of the canon of civil engineering practices [4]." Four years after that the American Planning Association (APA) adopted its Policy Guide on Planning for Sustainability [5]. While all three of these actions demonstrate an awareness of the environmental aspect of sustainable development what is also notable is how awareness of the social aspect lagged. The AIA originally made no mention of the social aspect, the ASCE recognized the social aspect, and the APA elaborated on the social aspect. Today, all three organizations recognize both aspects, and acknowledge environmentally sustainable solutions cannot be achieved through socially unsustainable means, specifically social injustice. 


\section{Sustainable development}

When talking about sustainable development it is critical to differentiate between growth and advancement. The notion of sustainable growth - be it sustainable world population growth or the sustainable growth of personal material wealth is only viable in the context of unlimited resources, which is to say it does not exist. Sustainable advancement is development that utilizes resources at rates equal to or less than the rates of replenishment. The two resources this paper focuses on are air and water.

\section{Disassociated bits of the whole}

Planners, architects and engineers in the United States who use the conventional approach to working on joint projects tend to have limited interaction with one another. Each discipline will work on their bit and then passes it on. The consequence of this type of process is the methods used by any one discipline to address a particular issue are often limited to those that are directly controlled by the discipline. Methods that require a high level of interdisciplinary integration are not used or not known.

What follows is a list of issues that have either emerged or undergone transformation in past couple of decades, but continue to be addressed independently by each discipline.

\subsection{Carbon footprint}

Carbon footprint is a measure of a person's environmental impact on the atmosphere due to greenhouse gas emissions. It is measured in unit mass of carbon dioxide equivalent per unit time - e.g. carbon dioxide equivalent in tonnes (metric tons) per year $(\mathrm{t} / \mathrm{yr})$ or pounds per year $(\mathrm{lb} / \mathrm{yr})$. The per capita carbon footprint in the United States is $19.7 \mathrm{t} / \mathrm{yr}(43,400 \mathrm{lb} / \mathrm{yr})$, according to 2007 data from the United Nations [6]. In the United Kingdom it is $9.0 \mathrm{t} / \mathrm{yr}$ $(19,800 \mathrm{lb} / \mathrm{yr})$.

In the United States, the use of fossil fuels in industrial agriculture accounts for a significant percentage of the carbon footprint; however, the actual amount is in dispute. The U.S. Environmental Protection Agency estimates it is $18 \%$, while Treehugger, an environment advocacy group, reports it may be as high as $30 \%$ [7]. Regardless of which number is more accurate, what is beyond dispute is industrial agriculture uses several calories of fossil fuel energy to produce one calorie of food energy [8,9]; and, in doing so transforms a carbon sequestering process - plant growth - into a carbon emitting process.

\subsection{Water footprint}

Water footprint is a measure of a person's direct and indirect consumption of water. It is measured in unit volume of water per unit time - e.g., cubic meters per year $\left(\mathrm{m}^{3} / \mathrm{yr}\right)$ or gallons per year $(\mathrm{gal} / \mathrm{yr})$. The per capita water footprint in the 
United States is $2,483 \mathrm{~m}^{3} / \mathrm{yr}(655,900 \mathrm{gal} / \mathrm{yr})$ [10]. In the United Kingdom it is $1,245 \mathrm{~m}^{3} / \mathrm{yr}(328,700 \mathrm{gal} / \mathrm{yr})$. Agriculture accounts for $58.7 \%$ of per capita water consumption in the United States with most of the water coming from sources inside the United States. In the United Kingdom it accounts for $65.1 \%$ with most of the water coming from sources outside of the United Kingdom.

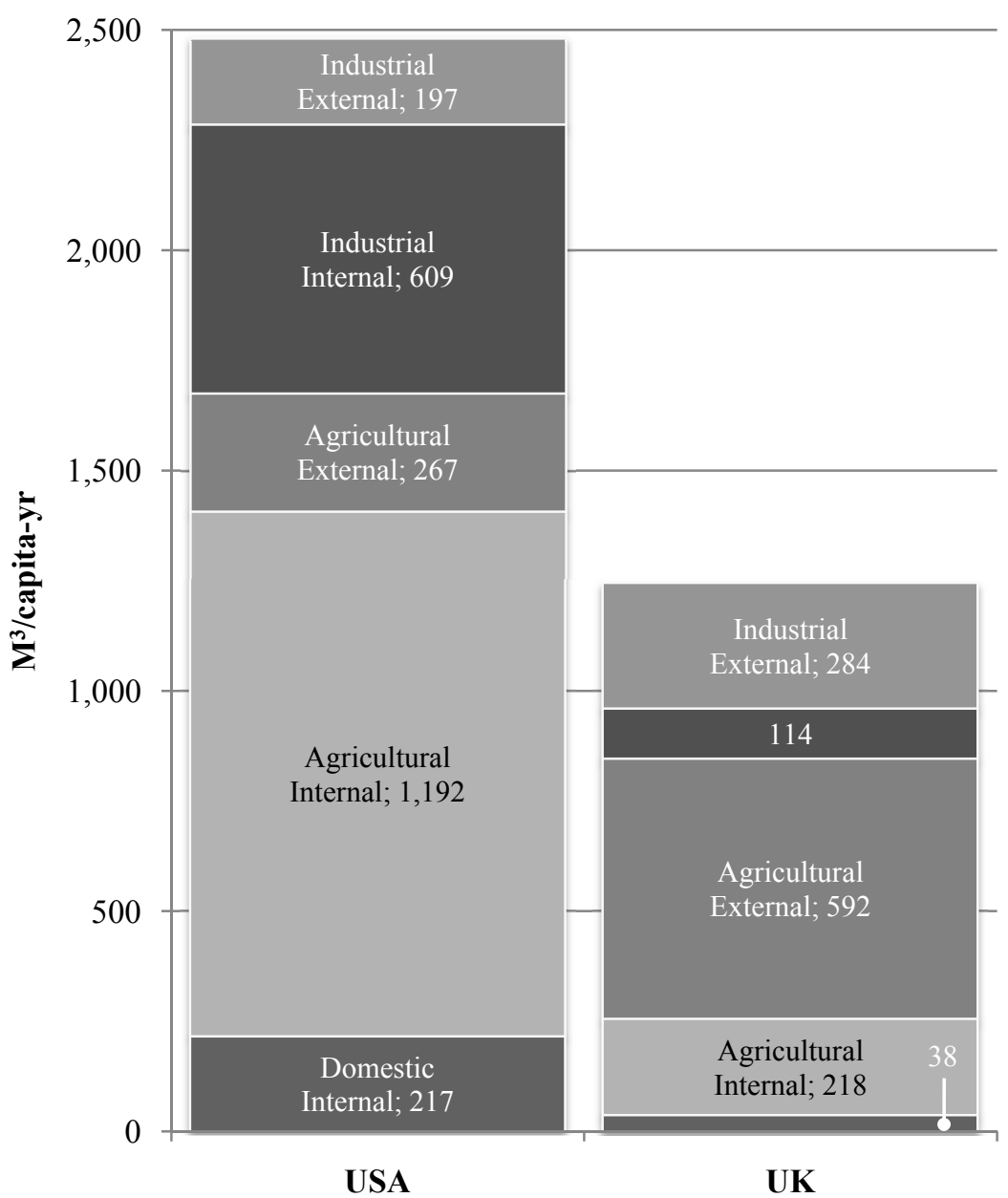

Figure 1: The per capita water footprints of the United States and United Kingdom from 1997 to 2001 are shown with end uses and sources broken out [11].

Water scarcity occurs when the water footprint exceeds the quantity of available water. Water scarcity is often transferred from one region to another region through indirect water consumption. Water scarcity in developing 
countries often results in social injustice due to women and the poor bearing a disproportionally large share of the burden. One of the leading causes of indirect water consumption and the transfer of water scarcity is the export-import of agricultural products.

\subsection{Rainwater}

Farmers tend to think of rainwater as a valuable resource. Until recently, most planners, architects and engineers in the United States tended to think of rainwater as a stormwater management problem that required the use of retention and detention ponds, catchments and storm sewers. Currently, most planners, architects and engineers who have adopted sustainable development design practices treat rainwater much in the same way they treat outdoor temperatures. Both are seen as environmental conditions that need to be managed on site. Sedum covered roofs are used to promote rainwater evaporation. Rain gardens and bioswales filled with ornamental plants are used to promote evaporation and percolation. Permeable surfaces are used to promote percolation. And, cisterns are used to collect rainwater for flushing toilets. Missing from all of these approaches is the notion of rainwater as a valuable resource.

\subsection{Food deserts}

A food desert exists when households in a geographic area have limited access to affordable nutritious food. It tends to happen most often in low-income neighbourhoods where households "... live far from a supermarket or large grocery store and do not have easy access to transportation [12]." The U.S, Department of Agriculture reports, “... 11.5 million people, or 4.1 percent of the total U.S. population, live in low-income areas more than 1 mile from a supermarket [12]." To the nearly complete exclusion of architects and engineers, it is planners who address food deserts. Methods for dealing with the issue include zoning, public transportation, community gardens and farmers' markets.

\section{$5 \quad$ Integrated design process}

The integrated design process (IDP) brings most, if not all, stakeholders of a project into the design process at the onset of the project, which differs from the conventional design process that brings stakeholders into the design process at various points during the development of the project. The benefit of the integrated design process over the conventional design process is it capitalizes on the opportunity to develop a high quality comprehensive solution by placing a large percentage of effort in the schematic design phase; whereas, the conventional design process places the greatest effort in contract documents phase to coordinate a collection of piecemeal solutions. Working in the integrated design process avoids the consequence of the conventional design process that was outlined above; that is, methods that require a high level of interdisciplinary integration are not used or not known. 


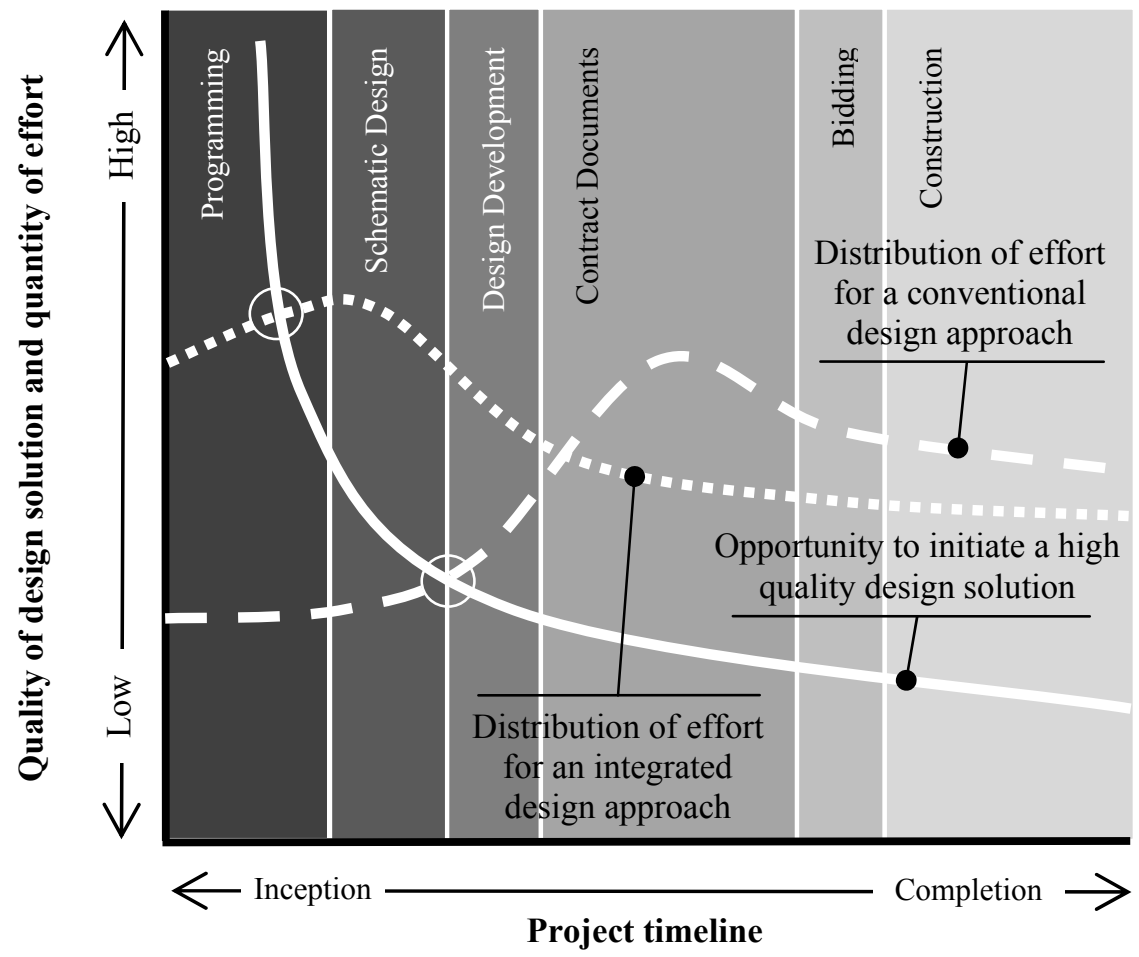

Figure 2: Conventional versus integrated design process.

\subsection{Integrating the bits into a whole}

Through the integrative design process it is possible to address the four bits listed above - carbon footprint, water footprint, rainwater and food deserts with the single solution of incorporating farming into urban architecture to produce agrarian urban architecture. Planting green roofs, rain gardens, bioswales and public spaces with fruits and vegetables transforms urban rainwater from a stormwater management problem to a vital resource for community gardens and urban CSA (community supported agriculture) farms that are widely distributed throughout the urban area, which work to eliminate food deserts. Diverting rainwater away from measures that promote evaporation towards measures that produce food reduces the water footprint. And, producing food locally eliminates the carbon footprint associated with transporting food long distances. The only real challenge is getting this information into the hands of the people who can best effect a change - emerging planners, architects and engineers.

The balance of this paper covers a two year effort by Dr. Brett Tempest, Assistant Professor of Civil and Environmental Engineering, and the author to teach agrarian urban architecture at the University of North Carolina Charlotte. 


\section{Agrarian urban architecture in higher education}

In the fall semester of 2009, Dr. Tempest and the author began teaching a multidisciplinary design studio that focused on precast and prestressed concrete as a structural system for various building types; and, the design of intentional communities containing senior cohousing and community supported agriculture. The studio serves undergraduate and graduate students in urban planning, architecture and engineering. The course pedagogy revolves around the integrated design process (IDP) to seek environmentally and socially sustainable solution for development.

\subsection{Enriching the IDP experience}

Enriching the IDP experience requires reaching out beyond the academic environment to farmers and experts in farming, the local food movement, agriburbia $^{\circledR}$ and more.

\subsubsection{Farmers and experts in farming}

The University of North Carolina Charlotte is located 14 miles southwest of the Cabarrus County Elma C. Lomax Incubator Farm. "This farm works much like a business incubator. Individuals interested in starting a business as a farmer can enroll in the program which provides classroom instruction on the business of farming in Cabarrus County as well as hands-on experience on the farm." "[It] supports local farming while encouraging a new generation of farmers to ensure quality local food sources flourish in Cabarrus County [13]."

The close proximity of the farm to the university campus makes it an excellent resource for students to develop some insight into the nuances of community supported agriculture (CSA) and organic farming. In addition to several acres of fields, the site includes a greenhouse, high tunnel, produce handling area, and other facilities.

\subsubsection{Local food}

Family farming in the Charlotte region extends back to when United States was still a British colony. Many farms in the area in the area are still owned by the same families that were deeded the farms by the King of England. It is this strong heritage in farming that drives the local food movement in the region. Support for the movement is so strong the County of Cabarrus created the position of local foods coordinator at a time when several county positions were being eliminated to deal with the downturn in the economy. Aaron Newton, coauthor of A Nation of Farmers: Defeating the Food Crisis on American Soil, was the original hire and continues to serve in the position. His workload includes routine visits to the studio to critique student work and give lectures.

\subsubsection{Agriburbia ${ }^{\circledR}$}

"Agriburbia ${ }^{\circledR}$ is [a] design movement and economic model that advocates for private development and re-development which integrates aspects of Agrarianism ..." It uses “... professional food production as a key element in the 
community design, social network, and financial viability of the development. Agriburbia provides a commercially viable mechanism for individuals and businesses to become more self sufficient and create truly sustainable communities [14]." Matthew Redmond is CEO of the TRS Group which developed the concept of agriburbia. He has visited the studio to talk about developing an agriburbia community.

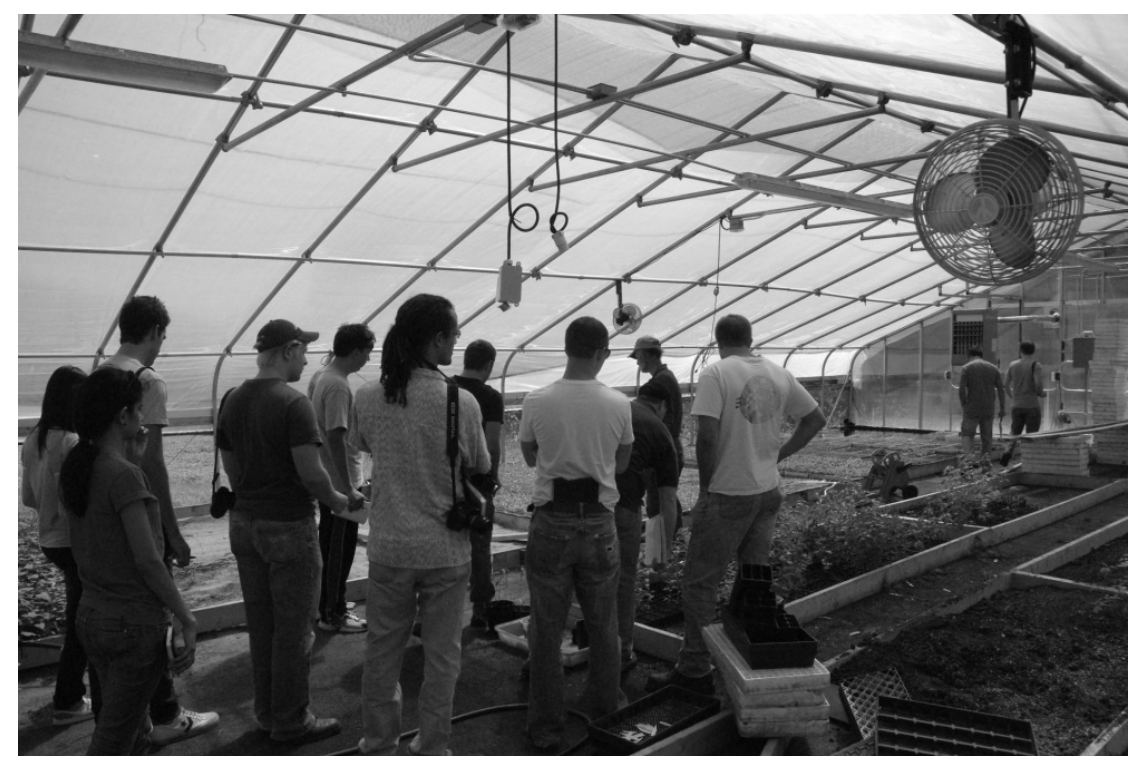

Figure 3: Architecture and engineering students visited the Cabarrus County Elma C. Lomax Incubator Farm where they received instruction on CSA farming from North Carolina Cooperative Extension staffers.

\subsection{Studio outputs}

The studio is yielding outputs beyond the educating of the students. One student is developing an intentional community containing senior housing and CSA farming for her capstone undergraduate project. Another student is researching urban agriculture for his M. Arch thesis. The Laboratory for Innovative Housing is partnering with Habitat for Humanity, the County of Cabarrus and the North Carolina Cooperative Extension to secure funding from the U.S. Department of Housing and Urban Development to research the role of local food in creating and maintaining sustainable low-income and affordable communities.

\section{Moving forward}

After teaching the studio for two years and seeing the outputs, it is clear planners, architects and engineers need to actively seek and engage the expertise of farmers and other people working in the local food movement; unfortunately, 
that clarity is not widely shared. Overcoming that lack of clarity is going to require farmers and other people working outside the spheres of planners, architects and engineers to insert themselves. One way to accomplish this is to host a workshop or design charette. In 2010 the Discovery Place - well known for its children's science museum - created the Charlotte Center for Urban Agriculture. In November it hosted the Visioning Workshop to explore and promote the role of urban agriculture.

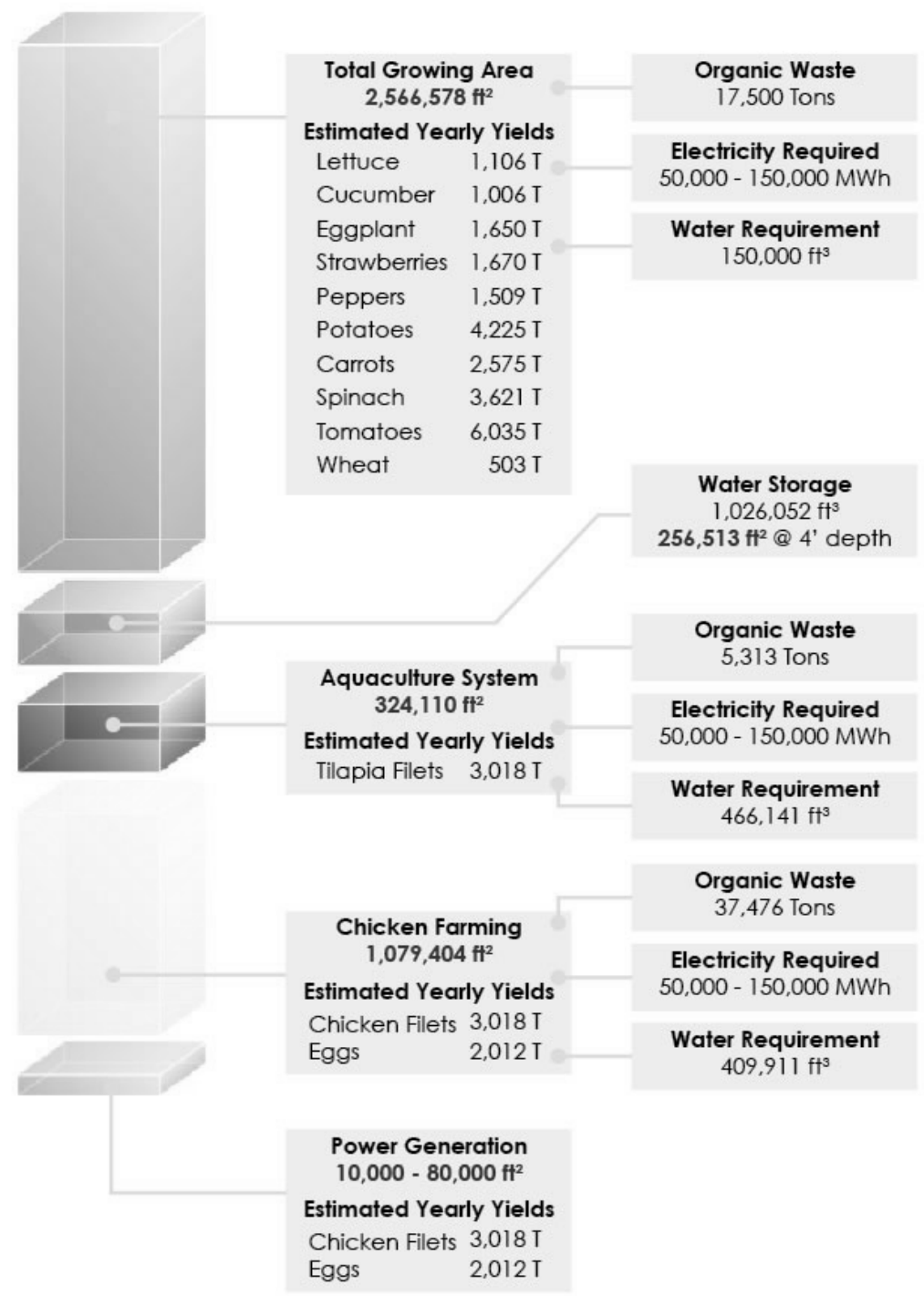

Figure 4: Summary of the production analysis for a vertical urban farm, produced by Frank Bates as part of his M. Arch thesis. 
In closing, the thought that is most important to remember is, agrarian urban architecture represents an advancement in sustainable development because it optimizes the utilization of resources while enhancing society.

\section{Acknowledgements}

The author gratefully acknowledges the PCI (Precast/Prestressed Concrete Institute) Foundation and Georgia/Carolinas PCI for their technical support and generous underwriting of the interdisciplinary integrated design studio.

\section{References}

[1] United States Department of Agriculture. Agriculture Factbook 2001-2002. Washington D.C. : U.S. Government Printing Office, 2003.

[2] Ag 101 Demographics. U.S. Environmental Protection Agency. [Online] 10 September 2009. [Cited: 24 February 2011.] http://www.epa.gov/oecaagct/ ag101/demographics.html.

[3] AIA Committee on the Environment. The American Institute of Architects. [Online] [Cited: 21 February 2011.] http://network.aia.org/AIA/ CommitteeontheEnvironment/Home/Default.aspx.

[4] ASCE \& Sustainability. ASCE American Society of Civil Engineers. [Online] 1996-2011. [Cited: 20 February 2011.] http://www.asce.org/ ProgramProductLine.aspx id=30338\&css=print.

[5] American Planning Association. Policy Guide on Planning for Sustainability. American Planning Association. [Online] 17 April 2000. [Cited: 21 February 2011.] http://www.planning.org/policy/guides/pdf/ sustainability.pdf.

[6] Millennium Development Goals Indicators. United Nations. [Online] [Cited: 20 February 2011.] http://mdgs.un.org/unsd/mdg/Data.aspx.

[7] Food + Health. Treehugger. [Online] 2010. [Cited: 20 February 2011.] http:/www.treehugger.com/files/2009/05/will-allen-industrial-agriculturemost- polluting-dangerous.php.

[8] Green, Maurice B. Eating Oil: Energy Use in Food Production. Boulder, CO : Westview Press, 1978.

[9] Astyk, S. and Newton, A. A Nation of Farmers: Defeating the Food Crisis on American Soil. Gabriola Island, BC : New Society Publishers, 2009.

[10] National Water Footprint Statistics. Water Footprint Network. [Online] 2011. [Cited: 20 February 2011.] http://www.waterfootprint.org/? page $=$ files/NationalStatistics.

[11] Hoekstra, A.Y. and Chapagain, A.K. Globalization of water: Sharing the planet's freshwater resources. Oxford, UK : Blackwell Publishing, 2008.

[12] Economic Research Service U.S. Department of Agriculture. Access to Affordable and Nutritious Food: Measuring and Understanding Food Deserts and Thier Consequences. Washington D.C. : U.S. Department of Agriculture, 2009. 
[13] Elma C. Lomax Incubator Farm. Cabarrus Local Food System. [Online] 22 June 2010. [Cited: 25 February 2011.] http://localfood.cabarruscounty.us/ Lists/Categories/Category.aspx?Name=Elma\%20C.\%20Lomax\%20Incubat or\%20Farm.

[14] Agriburbia-TRS Group. Agriburbia: Growing Sustainable Communities by the Bushel. [Online] 2010. [Cited: 25 February 2011.] http://www.agriburbia.com/index.html. 